\title{
Diastolic Blood Pressure as a Predictor of Mortality in Intracerebral Hemorrhage Stroke Patients with Hypertension
}

\author{
Cep Juli, ${ }^{1}$ Uni Gamayani, ${ }^{1}$ Nur Atik ${ }^{2}$ \\ ${ }^{1}$ Department of Neurology Faculty of Medicine Universitas Padjadjaran/Dr. Hasan Sadikin \\ General Hospital Bandung, Indonesia, ${ }^{2}$ Department of Biomedical Sciences Faculty of Medicine \\ Universitas Padjadjaran, Indonesia
}

\section{Abstract}

Background: Intracerebral hemorrhage (ICH) stroke contributes to a considerable number of deaths, ranging between $30 \%$ and $40 \%$ of the overall stroke mortality. The incidence of stroke increases with higher blood pressure. High blood pressure at the onset of ICH stroke is a strong predictor for mortality and morbidity. This study aimed to explore the role of diastolic blood pressure as a predictor of death in ICH stroke patients.

Methods: Data on 113 ICH stroke patients with chronic hypertension were collected from the medical records of patients treated in the Neurology ward of Dr. Hasan Sadikin General Hospital Bandung, Indonesia, in 2019. Data collected were patient characteristics, hypertension status, systolic and diastolic blood pressures, and patient outcome. Analysis was then performed using the Mann-Whitney test.

Results: This study revealed a positive correlation $(\mathrm{p}=0.031)$ between diastolic blood pressure and death in ICH stroke patients with chronic hypertension.

Conclusions: High diastolic blood pressure is associated with mortality in ICH stroke patients with chronic hypertension.

Keywords: Diastolic, intracerebral hemorrhage, predictor, stroke, systolic

\section{Introduction}

Stroke is a common cerebrovascular disease in which intracerebral hemorrhage (ICH) constitutes $10 \%$ to $15 \%$ of all strokes. The global incidence of ICH range is from 10 to 20 cases per 100,000 population. ${ }^{1-4}$ Riset Kesehatan Dasar (Riskesdas) 2018 in Indonesia has shown the stroke prevalence is $10.9 / \mathrm{mil}^{5}$ Stroke is the leading cause of death in the neurology, and most of the strokerelated death is due to ICH. The mortality rate of ICH stroke is found to be higher in low- and middle-income countries, and the majority of stroke-related deaths that occurred in this area are younger than 60 years old. In hospitalbased studies, the 30-day mortality ranges between $30 \%$ and $40 \%{ }^{6}$

Chronic hypertension is reported to be a major risk factor for ICH stroke. This chronic hypertension is found in $78-88 \%$ of patients with ICH stroke. ${ }^{1-4}$ According to the Joint National Committee (JNC) VII, the risk of a stroke starts when blood pressure is reaching $115 / 75 \mathrm{mmHg}$ and will double for every $20 \mathrm{mmHg}$ systolic and $10 \mathrm{mmHg}$ diastolic pressure increase. Systolic and diastolic blood pressures play a role in the occurrence of stroke. However, several studies suggested that starting from the age of 50 years old, diastolic blood pressure tends to decrease; thus, systolic blood pressure has a profound influence on the occurrence of stroke. ${ }^{7}$

An important mechanism involving hypertension as the risk for ICH stroke is the rupture of penetrating arteries triggered by chronic hypertension and an acute increase in normal arterial and capillary blood pressure. Chronic hypertension can result in changes in arterioles, which include fibrinoid necrosis,

Correspondence: Cep Juli, Department of Neurology Faculty of Medicine Universitas Padjadjaran/Dr. Hasan Sadikin General Hospital, Jalan Pasteur 38, Bandung, Indonesia, E-mail: cepjuli42@gmail.com 
lipohyalinosis, medial degeneration, and microaneurysm formation. ${ }^{8}$

Decreased level of consciousness is the most important prognostic sign among patients suffering from ICH strokes. Patients with a decrease in consciousness show a poor prognosis. All ICH stroke patients with a very severe decrease of consciousness died in the acute phase. Other factors that lead to poor prognosis in the acute phase of the ICH stroke are age, a poor score of 'National Institute of Stroke Scale' (NIHSS), location of the ruptured blood vessel, high hematoma volume $>30$ cc), high leukocyte count and random blood sugar (RBS) score, midline shift, hematoma expansion, secondary subarachnoid hemorrhage (SAH), hydrocephalus, and high blood pressure at the onset. ${ }^{3,6-9}$ High blood pressure at the onset of the ICH stroke is one of the predictors of high mortality and morbidity. Uncontrolled blood pressure in patients with ICH stroke leads to a poor prognosis in the form of a recurrent stroke or death. A sustained increase in blood pressure can cause the patient to have an enlarged hematoma. ${ }^{3}$

Previous studies have explored the role of systolic blood pressure and mean arterial pressure (MAP) score and their relationship with mortality in stroke patients with hypertension as the risk factor. Our study specifically sought to understand the role of diastolic blood pressure as a predictor of mortality in ICH stroke patients with hypertension as the risk factor.

\section{Methods}

This was a cross-sectional analytic observational study using retrospective secondary data from medical records of patients treated at the Neurology Ward Dr. Hasan Sadikin General Hospital, Bandung, Indonesia. Those patients were diagnosed as having ICH stroke with hypertension as the risk factor, and data were collected throughout the year 2019. The inclusion criteria of those patients were ICH stroke patients with head CT scan images but without contrast, presenting a hemorrhage that matched the type of hemorrhage caused by hypertension. Patients with signs of infection at presentation, diabetes mellitus (DM), and primary subarachnoid hemorrhage were excluded. Each patient record was coded anonymously to ensure confidentiality during statistical analysis. The protocol study was approved by the Research Ethics Committee of Universitas Padjadjaran.

Data were analyzed statistically by first testing the numerical data normality using the Shapiro-Wilk test. To compare the means of the numerical data that were normally distributed, the unpaired t-test was used. Meanwhile, the Mann-Whitney test was used for data that were not normally distributed. The categorical data were tested using the Chi-Square test with the Kolmogorov-Smirnov and Exact-Fisher tests used as the alternative tests when the requirements of the Chi-Square test could not be met. The $p$-value $\leq 0.05$ was considered significant.

\section{Results}

Total data from 113 ICH stroke patients were collected. The majority of the patients were male $(51.3 \%)$ and $<60$ years of age $(64.6 \%)$. The mean systolic blood pressure was $179.6 \pm 21.5 \mathrm{mmHg}$ and diastolic pressure was $101.1 \pm 10.9 \mathrm{mmHg}$. The mean arterial pressure (MAP) of the subjects was $127.0 \pm 12.7 \mathrm{mmHg}$. The predominant symptom of intracranial high pressure observed was a decrease in consciousness or somnolence in $70(61.9 \%)$ patients. The average leukocyte count was $11,676.5 \pm 3,623.8$ and the average random blood sugar level was $127.8 \pm 35.8$. Most of the ICH strokes were located in basal ganglia and internal capsule $(40.7 \%)$ with secondary SAH presentation (39.8\%), the midline shift $(9.7 \%)$ and hydrocephalus (11.5\%) (Table 1 ).

The outcome of patients with intracerebral hemorrhage stroke based on age and gender were compared, resulting in no statistical difference between patients' outcome and age or gender as shown in Table 2.

The outcome of patients with intracerebral hemorrhage stroke was compared based on various blood examinations, showing that the mean of leucocyte was higher in patients who died compared to those who were alive. Interestingly, the blood glucose was tended to higher in patients who had died, although the difference was not statistically significant.

The patient outcome was further compared based on increased intracranial pressure symptoms, including the level of consciousness which were decreased consciousness (somnolence), decreased consciousness (soporous), headache, vomiting, and seizure. The results showed that decreased consciousness (soporous) was a statistically significant difference between patient outcomes. Patients who had died were more soporous.

Blood pressure parameters observed, including systolic, diastolic, and mean arterial 
Table 1 Characteristic of Patients with Intracerebral Hemorrhage Stroke at Dr. Hasan Sadikin General Hospital year 2019

\begin{tabular}{|c|c|}
\hline Characteristic & n (\%) \\
\hline \multicolumn{2}{|l|}{ Gender } \\
\hline Male & $58(51.3)$ \\
\hline Female & $55(48.7)$ \\
\hline \multicolumn{2}{|l|}{ Age category } \\
\hline$<60$ years old & $73(64.6)$ \\
\hline$>60$ years & $40(35.4)$ \\
\hline \multicolumn{2}{|l|}{ Systolic blood pressure } \\
\hline Mean \pm Std & $179.6 \pm 21.5$ \\
\hline Median & 180.0 \\
\hline Range (min-max) & $120.0-240.0$ \\
\hline \multicolumn{2}{|l|}{ Diastolic blood pressure } \\
\hline Mean \pm Std & $101.1 \pm 10.9$ \\
\hline Median & 100 \\
\hline Range (min-max) & $80-150$ \\
\hline \multicolumn{2}{|l|}{ Mean arterial pressure } \\
\hline Mean \pm Std & $127.0 \pm 12.7$ \\
\hline Median & 126.7 \\
\hline Range (min-max) & $93.3-170$ \\
\hline \multicolumn{2}{|l|}{ Leukocyte count } \\
\hline Mean \pm Std & $11,676.5 \pm 3,623.8$ \\
\hline Median & 11,440 \\
\hline Range (min-max) & $4,650-26,530$ \\
\hline \multicolumn{2}{|l|}{ Random blood sugar level } \\
\hline Mean \pm Std & $127.8 \pm 35.8$ \\
\hline Median & 120.0 \\
\hline Range (min-max) & $81.0-338.0$ \\
\hline \multicolumn{2}{|l|}{ Symptoms of high intracranial pressure } \\
\hline Somnolence & $70(61.9)$ \\
\hline Soporous & $18(15.9)$ \\
\hline Headache & $48(42.5)$ \\
\hline Vomiting & $43(38.1)$ \\
\hline Seizure & $4(3.5)$ \\
\hline \multicolumn{2}{|l|}{ NIHSS score } \\
\hline Mean \pm Std & $11.5 \pm 4.9$ \\
\hline Median & 11 \\
\hline Range (min-max) & $3-25$ \\
\hline \multicolumn{2}{|l|}{ Radiology results } \\
\hline \multicolumn{2}{|l|}{ Location of hemorrhage } \\
\hline Basal ganglia/internal capsule & $46(40.7)$ \\
\hline Thalamus & $30(26.5)$ \\
\hline Pons & $9(8.0)$ \\
\hline Cerebellum & $6(5.3)$ \\
\hline Lobar & $14(21.2)$ \\
\hline \multicolumn{2}{|l|}{ Important radiological features } \\
\hline Secondary SAH & $45(39.8)$ \\
\hline Midline shift & $11(9.7)$ \\
\hline Hydrocephalus & $13(11.5)$ \\
\hline
\end{tabular}


Table 2 Outcome of Patients with Intracerebral Hemorrhage Stroke based on Age and Gender

\begin{tabular}{lccc}
\hline \multirow{2}{*}{ Variable } & \multicolumn{2}{c}{ Patient Outcome } & \\
\cline { 2 - 3 } & $\begin{array}{c}\text { Alive (n=90) } \\
\mathbf{n}(\%)\end{array}$ & $\begin{array}{c}\text { Dead (n=23) } \\
\mathbf{n}(\%)\end{array}$ & p-value \\
\hline Age category & & & 0.059 \\
$\quad<60$ year & $62(68.9)$ & $11(47.8)$ & \\
$\quad>60$ year & $28(31.1)$ & $12(52.2)$ & \\
Gender & & & 0.135 \\
$\quad$ Male & $43(47.8)$ & $15(65.2)$ & \\
Female & $47(52.2)$ & $8(34.8)$ & \\
\hline
\end{tabular}

pressure were all statistically higher in patients who had died as shown in Table 5.

The CT head scan features based on the location, including basal ganglia/internal capsule, thalamus, pons, cerebellum, lobar, presence of secondary SAH, midline shift, and hydrocephalus were compared between patients who survived and patients who died. Results showed that the location in secondary $\mathrm{SAH}$, midline shift, and hydrocephalus more occurred in the patients who died.

Table 3 Outcome of Patients with Intracerebral Hemorrhage Stroke based on Blood Examination and NIHSS Score

\begin{tabular}{|c|c|c|c|}
\hline \multirow[b]{2}{*}{ Variable } & \multicolumn{2}{|c|}{ Patient Outcome } & \multirow[b]{2}{*}{ p-value } \\
\hline & $\begin{array}{c}\text { Alive }(n=90) \\
n(\%)\end{array}$ & $\begin{array}{c}\text { Dead }(n=23) \\
n(\%)\end{array}$ & \\
\hline $\begin{array}{l}\text { Leukocyte count }(/ \mathrm{mm} 3) \\
\text { Mean } \pm \text { Std } \\
\text { Median } \\
\text { Range (min-max) }\end{array}$ & $\begin{array}{c}11,060.1 \pm 3,167.5 \\
10,795 \\
4,650-26,530\end{array}$ & $\begin{array}{c}14,088.7 \pm 4,315.9 \\
14,320 \\
7,330-26,000\end{array}$ & 0.0001 * \\
\hline $\begin{array}{l}\text { Leukocyte category } \\
\quad<10000 / \mathrm{mm}^{3} \\
>0000 / \mathrm{mm}^{3}\end{array}$ & $\begin{array}{l}34(37.8) \\
56(62.2)\end{array}$ & $\begin{array}{c}4(17.4) \\
19(82.6)\end{array}$ & 0.065 \\
\hline $\begin{array}{l}\text { Random blood sugar level (mg/dl) } \\
\text { Mean } \pm \text { Std } \\
\text { Median } \\
\text { Range (min-max) }\end{array}$ & $\begin{array}{c}123.0 \pm 27.2 \\
120 \\
81-240\end{array}$ & $\begin{array}{c}146.6 \pm 55.4 \\
132 \\
92-338\end{array}$ & 0.091 \\
\hline $\begin{array}{l}\text { Random blood sugar category } \\
\quad<140 \mathrm{mg} / \mathrm{dl} \\
\quad>140 \mathrm{mg} / \mathrm{dl}\end{array}$ & $\begin{array}{l}76(84.4) \\
14(15.6)\end{array}$ & $\begin{array}{l}12(52.2) \\
11(47.8)\end{array}$ & $0.001 *$ \\
\hline $\begin{array}{l}\text { NIHSS score } \\
\text { Mean } \pm \text { Std } \\
\text { Median } \\
\text { Range (min-max) }\end{array}$ & $\begin{array}{c}10.4 \pm 4.5 \\
10 \\
3-20\end{array}$ & $\begin{array}{c}15.5 \pm 4.1 \\
15 \\
10-25\end{array}$ & $0.0001 *$ \\
\hline $\begin{array}{l}\text { NIHSS category } \\
\quad \text { Mild } \\
\text { Moderate } \\
\text { Severe }\end{array}$ & $\begin{array}{l}11(12.2) \\
58(64.4) \\
21(23.3)\end{array}$ & $\begin{array}{c}0(0.0) \\
11(47.8) \\
12(52.2)\end{array}$ & $0.012 *$ \\
\hline
\end{tabular}

Note: NIHSS = National Institute of Stroke Scale; Std standard deviation; ${ }^{*} \mathrm{p}<0.05$. 
Table 4 Comparison of Various Increased Intracranial Pressure Symptoms and Outcome of Patients with Intracerebral Hemorrhage Stroke

\begin{tabular}{|c|c|c|c|}
\hline \multirow[b]{2}{*}{ Variable } & \multicolumn{2}{|c|}{ Patient Outcome } & \multirow[b]{2}{*}{ p-value } \\
\hline & $\begin{array}{c}\text { Alive }(n=90) \\
n(\%)\end{array}$ & $\begin{array}{c}\text { Dead }(n=23) \\
n(\%)\end{array}$ & \\
\hline \multicolumn{4}{|l|}{ Somnolence** } \\
\hline Yes & $59(65.6)$ & $11(47.8)$ & 0.118 \\
\hline No & $31(34.4)$ & $12(52.2)$ & \\
\hline \multicolumn{4}{|l|}{ Soporous** } \\
\hline Yes & $7(7.8)$ & $11(47.8)$ & $0.0001^{*}$ \\
\hline No & $83(92.2)$ & $12(52.2)$ & \\
\hline \multicolumn{4}{|l|}{ Headache } \\
\hline Yes & $41(45.6)$ & $16(696)$ & 0.190 \\
\hline No & 49 (54.4) & & \\
\hline \multicolumn{4}{|l|}{ Vomiting } \\
\hline Yes & $32(35.6)$ & $12(522)$ & 0.279 \\
\hline No & $58(64.4)$ & & \\
\hline \multicolumn{4}{|l|}{ Seizure } \\
\hline Yes & $3(3.3)$ & $22(957)$ & 1.000 \\
\hline No & 87 (96.7) & & \\
\hline
\end{tabular}

\section{Discussions}

This study has found several predictors of death in patients with ICH stroke; i.e. decreased consciousness, poor NIHSS score, leukocytosis, high random blood sugar level, secondary SAH, midline shift, hydrocephalus, systolic blood pressure, MAP, and diastolic blood pressure.

Decreased level of consciousness is the most important sign of poor prognosis in patients with ICH stroke. Decreased consciousness in patients with ICH stroke is caused by the effect of mass and increased intracranial pressure or

Table 5 Comparison of Blood Pressure and Outcome of Patients with Intracerebral Hemorrhage Stroke

\begin{tabular}{|c|c|c|c|}
\hline \multirow[b]{2}{*}{ Variable } & \multicolumn{2}{|c|}{ Patient Outcome } & \multirow[b]{2}{*}{ p-value } \\
\hline & $\begin{array}{c}\text { Alive } \\
(\mathrm{n}=90)\end{array}$ & $\begin{array}{c}\text { Dead } \\
(n=23)\end{array}$ & \\
\hline $\begin{array}{l}\text { Systolic blood pressure } \\
\text { Mean } \pm \text { Std } \\
\text { Median } \\
\text { Range (min-max) }\end{array}$ & $\begin{array}{c}176.7 \pm 19.3 \\
180 \\
120-220\end{array}$ & $\begin{array}{c}190.9 \pm 26.3 \\
190 \\
140-240\end{array}$ & 0.018 * \\
\hline $\begin{array}{l}\text { Diastolic blood pressure } \\
\text { Mean } \pm \text { Std } \\
\text { Median } \\
\text { Range (min-max) }\end{array}$ & $\begin{array}{c}100.2 \pm 107 \\
100 \\
80-150\end{array}$ & $\begin{array}{c}104.4 \pm 11.2 \\
100 \\
80-120\end{array}$ & $0.031 *$ \\
\hline $\begin{array}{l}\text { MAP } \\
\text { Mean } \pm \text { Std } \\
\text { Median } \\
\text { Range (min-max) }\end{array}$ & $\begin{array}{c}125.4 \pm 11.9 \\
126.7 \\
93-170\end{array}$ & $\begin{array}{c}133.2 \pm 14.3 \\
133.3 \\
100-160\end{array}$ & $0.004 *$ \\
\hline
\end{tabular}

Note: MAP mean arterial pressure; ${ }^{*} \mathrm{p}<0.05$; Std standard deviation 
Table 6 Comparison of CT-head Scan Feature based on Location and the Outcome of Patients with Intracerebral Hemorrhage Stroke

\begin{tabular}{|c|c|c|c|}
\hline \multirow[b]{2}{*}{ Variable } & \multicolumn{2}{|c|}{ Patient Outcome } & \multirow[b]{2}{*}{ p-value } \\
\hline & $\begin{array}{c}\text { Alive }(n=90) \\
n(\%)\end{array}$ & $\begin{array}{c}\text { Dead }(n=23) \\
n(\%)\end{array}$ & \\
\hline \multicolumn{4}{|c|}{ Basal ganglia/internal capsule } \\
\hline Yes & $38(42.2)$ & $8(34.8)$ & 0.517 \\
\hline No & $52(57.8)$ & $15(65.2)$ & \\
\hline \multicolumn{4}{|l|}{ Thalamus } \\
\hline Yes & $22(24.4)$ & $8(34.8)$ & 0.316 \\
\hline No & $68(75.6)$ & $15(65.2)$ & \\
\hline \multicolumn{4}{|l|}{ Pons } \\
\hline Yes & $6(6.7)$ & $3(13.0)$ & 0.313 \\
\hline No & $84(93.3)$ & $20(87.0)$ & \\
\hline \multicolumn{4}{|l|}{ Cerebellum } \\
\hline Yes & $5(5.6)$ & $1(4.3)$ & 1.000 \\
\hline No & $85(94.4)$ & $22(95.7)$ & \\
\hline \multicolumn{4}{|l|}{ Lobar } \\
\hline Yes & $10(22.2)$ & $4(17.4)$ & 0.613 \\
\hline No & $70(77.8)$ & $19(82.6)$ & \\
\hline \multicolumn{4}{|l|}{ Secondary SAH } \\
\hline Yes & 28 (31.1) & 17 (73.9) & $0.0001 *$ \\
\hline No & $62(68.9)$ & $6(26.1)$ & \\
\hline \multicolumn{4}{|l|}{ Midline shift } \\
\hline$<0.5 \mathrm{~cm}$ & $9(10.0)$ & $2(8.7)$ & \\
\hline$>0.5 \mathrm{~cm}$ & $5(5.6)$ & $12(52.2)$ & $0.0001 *$ \\
\hline No & $76(84.4)$ & $9(39.1)$ & \\
\hline \multicolumn{4}{|l|}{ Hydrocephalus } \\
\hline Yes & $2(2.2)$ & $11(47.8)$ & $0.0001 *$ \\
\hline No & 88 (97.8) & $12(52.2)$ & \\
\hline
\end{tabular}

Note: $\mathrm{SAH}=$ subarachnoid hemorrhage, ${ }^{*}=\mathrm{p}<0.05$

direct involvement of the reticular activation system of the brainstem. ${ }^{8}$

NIHSS is a stroke-specific quantitative scale that examines levels of consciousness, language function, neglect, visual field, eye movement, facial symmetry, motor strength, sensory, and coordination. NIHSS has been originally designed as a research tool to measure basic data in clinical trials on acute stroke patients. This scale is widely used as a clinical assessment tool to evaluate stroke patients, determine appropriate treatment, and can be considered to have a better predictive factor for neurological outputs in ICH stroke compared to the Glasgow Coma Scale (GCS) only. NIHSS correlates with the objective measure of stroke severity. Increasing NIHSS score reflects an unfavorable ICH stroke output. Poor NIHSS score is associated with hematoma volume at the onset of the ICH stroke.10

A high leukocyte count at onset is one of the predictors of death in patients with ICH stroke. Several reports have shown that in patients with ICH stroke, a correlation is found between increased leukocyte count at onset and initial neurological deterioration that will then lead to poor outcomes. Early leukocytosis is significantly associated with early neurological deterioration and mortality. Leukocytosis in ICH stroke patients is caused by increased catecholamine release and corticosteroid production that positively correlates with the hemorrhage volume. ${ }^{11}$

The random blood sugar level is associated with a high risk of mortality among ICH stroke patients. Studies have shown that patients with elevated random blood sugar levels have 
a higher incidence of brain complications and more extensive hemorrhage, recurrent hemorrhage, blood barrier destruction leading to brain edema exacerbation, neuronal apoptosis, and poor functional outcomes. A study showed that elevated random blood sugar level in patients with ICH stroke was an independent predictor of mortality in non-diabetic patients. Hyperglycemia in acute neurological injuries is associated with catecholamine surge and immune stress response. The elevated random blood sugar level reflects the severity of the stroke as a stress reaction to a serious brain injury. ${ }^{12}$

Secondary SAH, midline shift, and hydrocephalus are the next predictors of death in this study. Patients with ICH stroke are often deteriorating during the first 24-48 hours after onset. This deterioration can be explained by the ongoing hemorrhage but it is most frequently associated with the development of edema around the lesion, the effect of lesion on the blood flow, metabolism in the brain, brain tissue shift, and herniation. Mass-induced effects in patients with hematomas are more common than in patients with ischemia due to the volume of additional substances that add to the edema. Mostly, the effect of the hematoma pressure on the hemisphere results in the midline shift without herniation of the brain. When the effect of mass is severe, the brain tissue swells or protrudes into a different compartment, which is referred to as the process of herniation. A shift in the brain tissue can also cause compression or expansion of blood vessels and infarction of the area that receives blood supply from the artery and secondary hemorrhage. Blood can also enter the ventricular space, which will substantially increase the mortality risk. The ventricular system can also be compressed in various places. Hematomas in the putamen or cerebral lobes can damage the Monro foramen, causing dilatation of the contralateral lateral ventricles. The thalamus hematoma often blocks and compresses the third ventricle, causing hydrocephalus of both lateral ventricles. Cerebral hemorrhage can compress the IV ventricles or cerebral aqueduct, causing obstructive hydrocephalus from the third and lateral ventricles. Brain tissue shift, herniation, secondary infarction, blood entering the ventricles, and hydrocephalus lead to the worsening of the ICH stroke clinical signs and symptoms. ${ }^{8}$

Hypertension is the most important risk factor for ICH stroke. A meta-analysis on 68 blood pressure reduction trials showed that a reduction of $10 \mathrm{mmHg}$ of the systolic blood pressure and $5 \mathrm{mmHg}$ of diastolic blood pressure is associated with a reduction in the incidence of stroke by $36 \%$ and a reduction in the mortality caused by cardiovascular disease by $16 \%{ }^{13}$ In many cases, patients with ICH stroke are assigned in the hypertensive crisis criteria. In a hypertensive crisis, the systolic blood pressure reaches $180 \mathrm{mmHg}$ and the diastolic pressure becomes very high, up to $120 \mathrm{mmHg} .{ }^{14,15}$ The role of systolic and diastolic blood pressures in ICH stroke cannot be ignored because each of them independently affects the blood vessels. ${ }^{16}$ A previous study has reported that high diastolic blood pressure damages the endothelium of the intracerebral arteries, causing rupture of the blood vessels. ${ }^{17}$ ICH stroke occurs spontaneously when a weak blood vessel in the brain ruptures and increases the intracranial pressure, causing damage to brain cells around the hematoma. High blood pressure is associated with hematoma growth expansion that results in poorer functional outcomes and increased mortality risk. Onethird of patients with ICH stroke rapidly develop hematoma during the first few hours of the stroke. The leaking blood also displaces and compresses the surrounding tissue. ${ }^{18}$

The limitation of this study is that this study has been conducted in a single center hospital, therefore, a larger multicenter study is recommended to further validate the result. Another limitation is that no data available on the blood volume of the hemorrhage image from the head CT Scanasthis might be important predictors of death in ICH stroke.

In conclusion, diastolic blood pressure can be used as a predictor of death in ICH stroke patients with hypertension as the risk factor.

\section{References}

1. Zaidi G, Chichra A, Weitzen, Narasimha M. Blood pressure control in neurological ICU patients: what is too high and what is too low?.The Open Critical Care Medicine Journal. 2013:6(Suppl 1:M3): 46-55

2. Sacco RL, Kasner SE, Broderick JP, Caplan LR, Connors JJB, Culebras A, et al. An updated definition of stroke for the 21st century: a statement or healthcare professionals from the American Heart Association/American Stroke Association. Stroke. 2013;44(7): 2064-89

3. Hwang SK, Kim JS, Kim HJ, Hong CK, Yang $\mathrm{KH}$. Antihypertensive treatment of acute intracerebral hemorrhage by intravenous nicardipine hydrochloride: prospective 
multi-center study. J Korean Med Sci. 2012;27(9):1085-90

4. Nakalema I, Kaddumukasa M, Nakibuuka J, Okello E, Sajatovic M, Katabira E. Prevalence, patterns and factors associated with hypertensive crises in Mulago hospital emergency department; a cross-sectional study. Afr Health Sci.2019;19(1):1757-67

5. Badan Penelitian dan Pengembangan Kesehatan Kementerian Kesehatan Republik Indonesia. Laporan nasional riset kesehatan dasar (Riskesdas) 2018. Jakarta: Badan Penelitian dan Pengembangan Kesehatan Kementerian Kesehatan Republik Indonesia; 2019

6. Goswami D, Sharma T, Das CK, Choudhury B, Bharadwaj R. Prognostic factors in intracerebral hemorrhage: a hospital based prospective study. Int J Med Res Prof. 2016;2(5):32-9

7. Chobanian AV, Bakris GL, Black HR, Cushman WC, Green LA, Izzo Jr. JL, et al. Seventh report of the Joint National Committee on Prevention, Detection, Evaluation and Treatment of High Blood Pressure. Hypertension. 2003; 42(6):1206-52

8. Caplan LR. Introduction and perspective. In: Caplan LR , editor. Caplan's stroke: a clinical approach. $5^{\text {th }}$ ed. Cambridge: Cambridge University Press; 2016. p. 1-18

9. An SJ, Tae Jung Kim TJ, Yoon BW. Epidemiology, risk factors, and clinical features of intracerebral hemorrhage: an update. J Stroke. 2017;19(1):3-10

10. Mahdy ME, Ghonimi NA, Elserafy S, Mahmoud W. The NIHSS score can predict the outcome of patients with primary intracerebral hemorrhage. Egypt J Neurol Psychiatr Neurosurg. 2019;55(1):21

11. Behrouz R, Hafeez S, Miller CM. Admission leukocytosis in intracerebral hemorrhage: associated factors and prognostic implications. Neurocrit Care. 2015;23(3): 370-3

12. Kongwad LI, Hegde A, Menon G, Nair R. Influence of admission blood glucose in predicting outcome in patients with spontaneous intracerebral hematoma. Front Neurol. 2018; 9: 725

13. Flint AC, Conell C, Ren X, Banki NM, Chan SL, Rao VA, et al. Effect of systolic and diastolic blood pressure on cardiovascular outcomes. N Engl J Med. 2019;381(3): 243-51

14. Marik PE, Varon J. Hypertensive crises: challenges and management. Chest. 2007;131(6):1949-62

15. Rodriguez MA, Kumar SK, De Caro M. Hypertensive crisis. Cardiol Rev. 2010;18(2):102-7

16. Seitz RJ, Donnan GA. Recovery potential after acute stroke. Front Neurol. 2015; 6: 238

17. Vishram JKK, Borglykke A, Andreasen $A H$, Jeppesen J, Ibsen $H$, Jørgensen $T$, et al. Impact of age on the importance of systolic and diastolic blood pressures for stroke risk: the MOnica, Risk, Genetics, Archiving, and Monograph (MORGAM) Project. Hypertension. 2012;60(5):1117-23.

18. Parmar P. Stroke: classification and diagnosis. Clinical Pharmacist. 2018; 10(1):DOI:10.1211/PJ.2018.20204150 